\title{
Spotlight on Music Collections: The Canadian Women Composers Collection
}

This interview focuses on the work of Kevin Madill, Music Librarian at the Music Art and Architecture Library at the University of British Columbia (Vancouver, BC). He describes a recently developed collection focused on the contributions of Canadian women composers, including his work engaging with donors, and some of the unique challenges associated with acquiring contemporary compositions. Spotlight on Music Collections aims to profile interesting or unique music collections in Canada through the voices of those who work with them. If you have a suggestion for a collection or individual that should be featured in a future edition of this column, please reach out to carolyn.doi@usask.ca.

\section{What is the Canadian Women Composers Collection?}

The Canadian Women Composers Collection (CWCC) was introduced by the UBC Library in 2015 for the purpose of documenting the compositional practices of Canadian women composers active at home or abroad. The collection serves to build and sustain a body of unique materials that will serve future musicologists, music theorists, and performers interested in music analyses, as well as expand participating composers' audiences.

The following are participating composers to date: Deborah Carruthers (Montréal, QC), Dorothy Chang (Vancouver, BC), Zosha di Castri (New York, NY), Barbara Monk Feldman (Guelph, ON), and Ana Sokolović (Montréal, QC). March 2021, the collection expands with contributions from Lori Freedman (Montréal, QC) and Chiyoko Szlavnics (Berlin, Germany). Materials were created and assembled by the respective composers during the course of their activities.

The physical collection can be accessed through Rare Books and Special Collections, UBC Library. ${ }^{1}$ Parts of the collection have been digitized and are available through UBC Library's Open Collections or online exhibitions. ${ }^{2 / 3}$

\section{How did you get the idea to start the collection?}

The CWCC is the result of a chance encounter. I've always been amenable to meeting library donors, even those not interested in supporting music collections. I remember taking a call from UBC Library Development asking if I'd be available to meet with a community member and library advocate seeking a tour of our facilities. That advocate turned out to be Anne Kaplan, an

\footnotetext{
1 “Collection RBSC-ARC-1817 - Canadian Women Composers collection," University of British Columbia Library Rare Books and Special Collections, https://rbscarchives.library.ubc.ca/index.php/canadian-women-composers-collection

2 UBC Library Digitization Centre Special Projects, 'slippages,' https://open.library.ubc.ca/search?q=slippages\&collection=specialp

3 “'Slippages': An Interdisciplinary Project in the Arts and Humanities," UBC Open Collections, https://ubc-ds.github.io/slippages/
} 
established Vancouverite with a history of success in the local business world. Our initial meeting grew into regular conversations over coffee. Anne talked about her life in business which prompted ongoing deliberations on women composers in Canada as entrepreneurs and how the UBC music collection might offer them support. I was truly surprised to hear of Anne's sudden death and that Anne had bequeathed an endowment to UBC's music collection. I returned to our past conversations to consider how best to transform Anne's generous gift into an expression of her desire to help other bold and innovative women. This was the beginning of the CWCC.

Can you describe one of your favourite items from the collection?

Zosha di Castri offered to the CWCC the first rehearsal draft of Sprung Testament. ${ }^{4}$ The score shows handwritten edits consequent to the collaborative process between the composer and violinist Jennifer Koh just prior to the opening night performance. It's always exciting to see such handwritten edits revealing moments of inspiration and resolution.

\section{Currently, can you share one of the biggest challenges of building this collection?}

The biggest challenge of working with this collection is that there is no shortage of amazing ideas. There are lots of challenges related to building the CWCC. One of the biggest has to do with contemporary composers using software in the compositional process. Our archives privilege print and are without a process for accessioning e-resources. The future is coming but not yet! My job in these circumstances is to find creative ways of capturing the utilization of such programs through print.

\section{Can you share one of your favourite things about working on this project?}

What I enjoy most about building the CWCC is connecting people who might not otherwise meet. In 2020, Ana Sokolović's submission to the CWCC, II divertimento barocco, was to be premiered by the string section of a major Canadian orchestra. Unfortunately, the performance was cancelled due to COVID-19. On hearing this, I had the idea to connect Ana with Jonathan Girard, Conductor, University of British Columbia Symphony Orchestra to see if the UBCSO might premiere the work instead. An excerpt from the resulting performance can be found online. ${ }^{5}$

\section{How do you hope the collection will grow in upcoming years?}

The CWCC is an opportunity to support Canadian women composers professionally and financially, and support researchers and knowledge users in their diverse engagements in music discourse. My intent is to continue to offer that support. When I move out of this position, my hope is that the

\footnotetext{
4 "File 02-16 - Sprung Testament - Early Score with Notes," RBSC-ARC-1817-02-16, University of British Columbia Library Rare Books and Special Collections, https://rbscarchives.library.ubc.ca/sprung-testament-earlyscore-with-notes.

${ }^{5}$ UBC School of Music, “UBCSCO Presents Two World Premiers!” Dec. 2, 2020, https://fb.watch/4kCXeY7MjH/.
} 
next music librarian at UBC continues to search for innovative ways to support creative people in the arts in this country - if not through the CWCC than through some other means. One of the most impactful things you can do through projects like the CWCC is to let creative people know that you see them and recognize their accomplishments.

Thank you for taking the time to describe your work on this collection. Is there anything else you'd like to add?

Yes, please. I would like to thank Anne Kaplan, the donor whose financial contribution made the CWCC endowment possible. I also want to thank all the participating composers in the CWCC for their kindness, generosity, and approachability; you have brought a lot of joy into my life as well as finding a welcoming home for your music sketches and scores. 